Check for updates

Cite this: Phys. Chem. Chem. Phys., 2017, 19, 20904

Received 23rd January 2017, Accepted 11th July 2017

DOI: $10.1039 / \mathrm{c} 7 \mathrm{cp} 00518 \mathrm{k}$

rsc.li/pccp

\title{
Materials space of solid-state electrolytes: unraveling chemical composition-structure-ionic conductivity relationships in garnet-type metal oxides using cheminformatics virtual screening approaches $\dagger$
}

\begin{abstract}
Natalia Kireeva (D)*ab and Vladislav S. Pervov ${ }^{c}$
The organic electrolytes of most current commercial rechargeable Li-ion batteries (LiBs) are flammable, toxic, and have limited electrochemical energy windows. All-solid-state battery technology promises improved safety, cycling performance, electrochemical stability, and possibility of device miniaturization and enables a number of breakthrough technologies towards the development of new high power and energy density microbatteries for electronics with low processing cost, solid oxide fuel cells, electrochromic devices, etc. Currently, rational materials design is attracting significant attention, which has resulted in a strong demand for methodologies that can accelerate the design of materials with tailored properties; cheminformatics can be considered as an efficient tool in this respect. This study was focused on several aspects: (i) identification of the parameters responsible for high Li-ion conductivity in garnet structured oxides; (ii) development of quantitative models to elucidate composition-structure-Li ionic conductivity relationships, taking into account the experimental details of sample preparation; (iii) circumscription of the materials space of solid garnet-type electrolytes, which is attractive for virtual screening. Several candidate compounds have been recommended for synthesis as potential solid state electrolyte materials.
\end{abstract}

\section{Introduction}

Solid state inorganic electrolytes enable a number of breakthrough technologies towards the development of new high power and energy density microbatteries for electronics with low processing cost ${ }^{1}{ }^{\text {solid }}$ oxide fuel cells, ${ }^{2}$ electrochromic devices, ${ }^{1,3,4}$ and many others. The organic electrolytes of most current commercial rechargeable Li-ion batteries (LiBs) are flammable, toxic and have limited electrochemical energy windows. All-solid-state battery technology promises improved safety, cycling performance, electrochemical stability and possibility of device miniaturization. Additionally, solid electrolytes would enhance the energy density by reviving metallic Li anodes technology.

\footnotetext{
${ }^{a}$ Frumkin Institute of Physical Chemistry and Electrochemistry Russian Academy of Sciences, Leninsky Prospect, 31a, 119071, Moscow, Russia.

E-mail: nkireeva@gmail.com, kireeva@phyche.ac.ru; Tel: +7 4959554666

${ }^{b}$ Moscow Institute of Physics and Technology (State University), Institutsky per., 9, 141700, Dolgoprudny, Russia

${ }^{c}$ Kurnakov Institute of General and Inorganic Chemistry Russian Academy of Sciences, Leninsky Prospect, 31a, 119071, Moscow, Russia

$\dagger$ Electronic supplementary information (ESI) available: The collected data used in this study. See DOI: $10.1039 / \mathrm{c} 7 \mathrm{cp} 00518 \mathrm{k}$
}

In recent decades, a large number of inorganic materials, including LISICONs-like and NASICONs-like compounds, perovskites, antiperovskites, garnets, argyrodites, Li nitrides, halides and hydrides, and LIPONs, with both crystalline and amorphous structures as well as their composite structures have been investigated experimentally and theoretically as potential solid electrolyte candidates. ${ }^{5-12}$

Rational materials design to accelerate materials development processes is attracting much attention, initiated to some extent by growing interest in alternative green energy storage and conversion technologies, ${ }^{13-21}$ which has resulted in a strong demand for methodologies that can ascertain materials candidates with tailored properties; cheminformatics (or materials informatics) can be used as an efficient tool in this respect. ${ }^{14-20,22-39}$

There are a number of requirements ${ }^{40}$ that materials must satisfy to be used as solid electrolytes in all-solid-state batteries: high total $\mathrm{Li}^{+}$-ion conductivity $\left(\sigma_{\mathrm{Li}}>10^{-4}\right)$ with a transference number close to unity $\left(\sigma_{\mathrm{Li}} / \sigma_{\text {total }} \approx 1\right)$, a high electrochemical stability window $(\sim 6 \mathrm{~V})$ with elemental $\mathrm{Li}$ or Li alloy, negligible electronic conductivity $\left(\sigma_{\mathrm{e}}<10^{-10}\right)$, retention of the electrode/ electrolyte interface during cycling, environmental safety of materials, negligible solid-state electrode-electrolyte interface 
charge transfer resistance, chemical stability over the operation temperature range, etc.

The current study is aimed at identifying the parameters responsible for high Li-ion conductivity in the garnet-structured oxide family of solid electrolytes that are attractive candidates for high power and energy all-solid state $\mathrm{Li}$ ion batteries ${ }^{41}$ due to a number of benefits, including their high $\mathrm{Li}$ ion conductivities, stability against $\mathrm{Li}$ anodes, and small grain boundary resistance. This study considers the total Li-ion conductivity as the target property, focusing on the development of quantitative models to elucidate chemical composition-structure-ionic conductivity relationships and endeavoring to consider materials synthesis and processing information (experimental method, effects of temperature, time and atmosphere of sintering, etc.). Other specified requirements for electrolytes are expected to be satisfied by the intrinsic properties of garnet type oxides.

The study was carried out by applying machine learning approaches related to two different groups of methods. The Li ion transport characteristics of the collected data were analyzed by combining regression analysis, thus elucidating the compositionstructure-ionic conductivity relationships and surveying garnetrelated structures for promising compositions with data visualization techniques, known in computer-aided molecular design as chemography or cartography approaches; this provided a bird's eye view of the materials space of solid electrolytes, which is attractive for virtual screening. Both groups of methods ${ }^{29,42-46}$ are based on the chemical similarity principle, which claims similar property values for similar compounds; the latter methods posit a correspondence between the positioning of the compounds in the chemical space defined by the ensemble of selected parameters (descriptors) that are identified to be responsible for the target properties and the structural similarity.

Among the most promising garnet-type solid electrolytes are $\mathrm{Al}^{3+}$, $\mathrm{Ga}^{3+}$ and $\mathrm{Fe}^{3+}$-stabilized $\mathrm{Li}_{7} \mathrm{La}_{3} \mathrm{Zr}_{2} \mathrm{O}_{12}$ (LLZO). These compounds are the object of increasing attention due to their high $\mathrm{Li}$ ionic conductivities and interesting phase structure behavior in response to doping. It was recently shown that $\mathrm{Ga}^{3+}$ - and $\mathrm{Fe}^{3+}$-stabilized LLZO can crystallize in alternative cubic space group $I \overline{4} 3 d$ (No. 220) to the cubic polymorph great while considered as the only (SG $I a \overline{3} d$; No. 230). The reasons for the phase transition and formation of this SG are related to the site preferences of $\mathrm{Ga}^{3+}$ and $\mathrm{Fe}^{3+}$ cations, which may be related to size factors. ${ }^{47}$ Several studies have been published on the local structure and site occupancy preferences of $\mathrm{Al}^{3+}$ and $\mathrm{Ga}^{3+}$ substituents. ${ }^{4-52}$ Thus, another aim of this study is an attempt to offer insight on the relative $24 d$ and $96 h$ site occupancy by dopants using grid search and setting-up ionic radii values of $\mathrm{Al}^{3+}$ and $\mathrm{Ga}^{3+}$ cations for each compound. The correspondence of predicted by the model ionic conductivity values with known experimental ones served as a criterion for establishing relative $24 d$ and $96 h$ site occupancy.

\section{Methodology}

Despite the substantial progress in materials informatics, only a few published studies are closely related to the objects of our research. In ref. 16, the authors apply density functional theory computation and an artificial neural network for modeling Li ion transport (migration energy) in tavorite-type structures in order to optimize these well-known cathode material structures for application as solid-state electrolyte materials. Using cathode and solid electrolyte related to the same structural type would be beneficial in order to decrease possible interface resistance. Structural information (lattice parameters, ion effective charges, intra- and interpolyhedron parameters) obtained as a result of DFT computations have been used as descriptor values. Candidate compositions have been proposed. In ref. 15 and 17, a combination of DFT with machine learning methods (partial least squares or artificial neural networks) was used for virtual screening of olivine-type materials for solid electrolyte applications (with Li ion hopping energy as a predicted property). Similar with previous study of the same group, they perform the screening of olivine-related compounds for compositions with suppressed electronic contribution in conductivity value. In ref. 14, first principles calculations were combined with support vector regression for modeling Li ion conductivity values in LISICON-type materials; diffusion coefficients, transition temperatures, formation free energies of solid solutions and average volumes of disordered structures were used as descriptor values.

The details of our study are organized as separate paragraphs and are given below.

\subsection{Data and descriptors}

The main dataset encompasses information related to garnettype oxide structures exhibiting high total conductivities at ambient temperature, desirable chemical and electrochemical stabilities, small grain boundary resistances, and Li transference numbers close to unity, which make them of substantial interest for use as solid electrolytes in all-solid-state batteries. This information includes the total Li-ion conductivities (sum of the bulk and grain boundary contributions), corresponding activation energy values, unit cell parameters if available, experimental details of synthesis, resulting product densities, types of pressure (uniaxial or isostatic) if available, etc. of garnet-type structure metal oxides with the general formula $\mathrm{A}_{3} \mathrm{~B}_{2}\left(\mathrm{XO}_{4}\right)_{3}$, whose $\mathrm{A}, \mathrm{B}$, $\mathrm{X}$ - eight, six and four oxygen coordinated cation sites are known to crystallize into crystal structures in two cubic space groups $(I a \overline{3} d$; No. 230 and $I \overline{4} 3 d)$ as well as one tetragonal space group (I4/ /acd; No. 142).

The distribution of the initial dataset according to reported experimental values of their total ionic conductivities as well as the taxonomy of the data in use are given in Fig. 1. This data is provided as ESI. $\dagger$

At the dataset preparation stage, only compounds with total ionic conductivity values evaluated at ambient temperatures were included (data measured at high temperatures have been omitted). Also we removed the compounds related to tetragonal crystal structure if the information about this compound as about the cubic polymorph has been represented in other publications from the data. Another reason for data removal is observed data variance. Even for compounds obtained using 


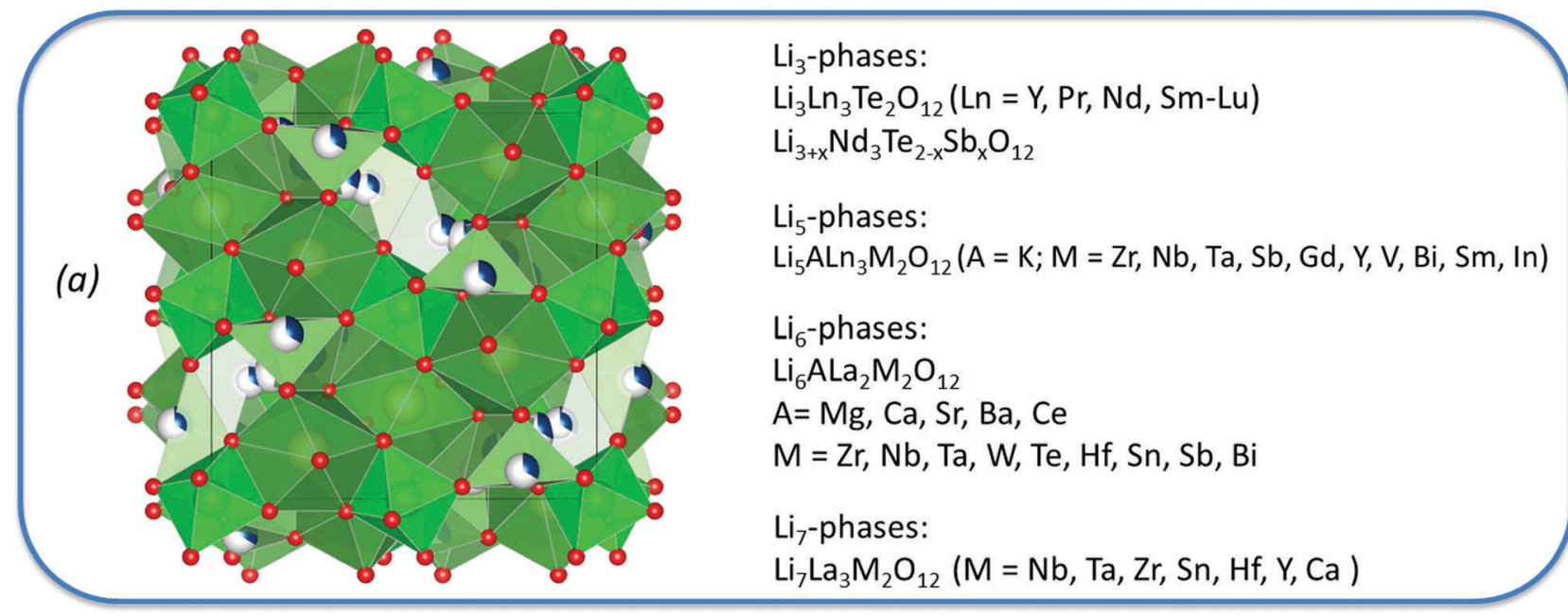

(b)

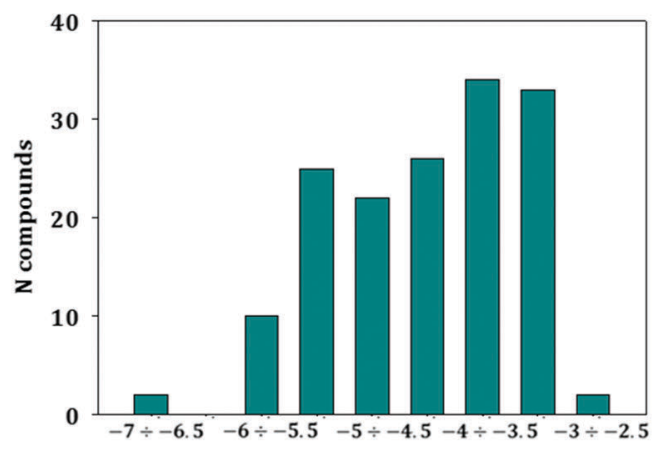

LOG(TOTAL CONDUCTIVITY)

Fig. 1 The taxonomy of the collected data (a) with its distribution according to reported experimental values of total ionic conductivity (b).

the same synthesis methodology, one can see that the evaluated Li ion total conductivity values varied in a wide range up to several orders of magnitude (see Fig. 2 and Table 1).

The decisions in this case were made ad hoc, i.e. considering each situation individually (compounds under consideration were removed in cases of discrepancy with a prominent number of observations for the same compound obtained using the same synthesis method). One more reason for exclusion was an estimated relative density of the sample $(<50 \%)$ that was essentially different from most of the observations in the data.

In fact, the problem of data curation, which is well-known in cheminformatics, bioinformatics and chemogenomics, ${ }^{53-55}$ acquires special importance here due to the necessity to analyze the reasons for such discrepancies. It acquires a wider meaning and combines aspects related to the critical assessment of published experimental data ${ }^{56-59}$ with the problem of controllable design of materials with desired characteristics; this is of practical importance, for example, in the design of hybrid electrolyte/Li metal anode structures in which garnet-based solid state electrolytes (SSE) have porous/dense bilayer structures with porous sublayers as a host for infiltrated lithium metal anodes ${ }^{60}$ (the possibility to rationally design products with specified characteristics is highly desirable and requires a clear understanding of the relationships between the synthesis method/conditions and final product characteristics).
The attempt to explicitly analyze the impact of materials synthesis information on the materials properties was the reason for including descriptors to encode materials synthesis information as well as for using several computational procedures reflected in different corresponding data sets that were issued from the initial data or coincide with it.

Thus, two different data preparation protocols have been used: in accordance with the first one, in cases where several compounds are present, only the first compound in the list was stored irrespective of the synthesis method or other experimental conditions (123 compounds). This was also performed for the alternative computations, where only the compounds obtained by conventional solid-state reactions have been included (106 compounds). In parallel, we decided to average out the $\log \sigma_{\text {tot }}$ values in cases where several compounds were present.

Another difference has been specified for the development of models involving space filling parameters (see below), where only compounds with available information on their lattice constants have been considered (the data set encompasses 98 compounds).

The whole dataset used in combination with descriptors encoding materials synthesis information encompasses 168 compounds.

Several types of parameters related to different categories were used as descriptors for the model development. Most of these 


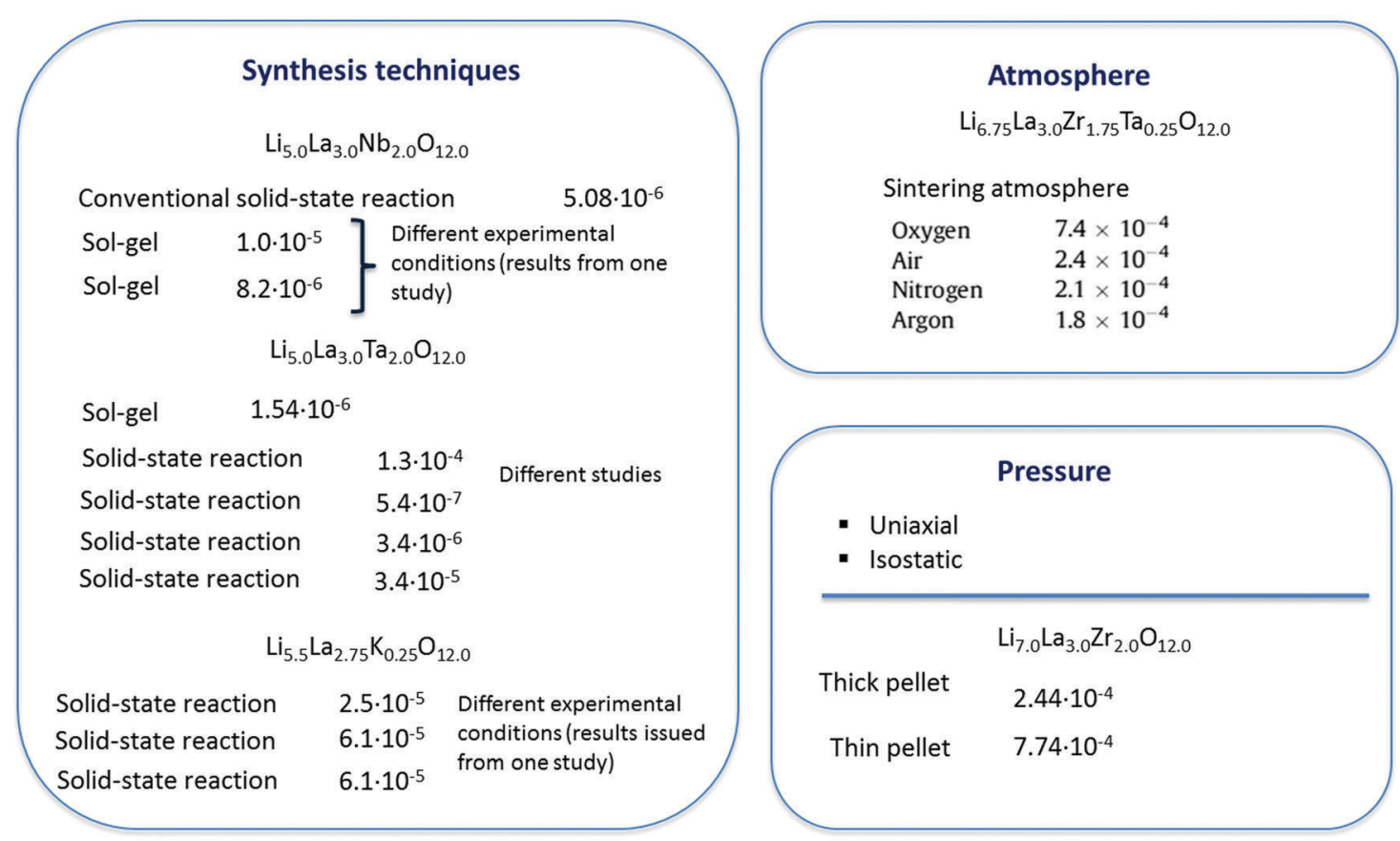

Fig. 2 The impact of experimental technique on the electrochemical performance of solid electrolytes: reported total conductivity values $\left(\mathrm{S} \mathrm{cm}^{-1}\right)$ as a function of processing method.

are geometry-based and stem from the interrelations of constituent element radii with geometric principles of ion packing as well as currently published studies where the most well known specific chemistries and structural type parameters responsible for $\mathrm{Li}$ ion conductivity were related to the geometrical point of view ${ }^{61}$ (Fig. 3).

Constitutional (compositional) descriptors describe the composition of compounds per formula unit ( $\mathrm{pfu}$ ), taking into account the corresponding structure type by means of the compound fingerprint bit string. For each cation type (in the case of garnet-related structures, tetrahedrally, octahedrally or dodecahedrally coordinated), three positions in this string are allocated. The first one is the position of the cation most commonly accommodated in the given site; the remaining two are reserved for substitution elements. The same scheme is used for other descriptors.

Shannon ionic radii values take into account the coordination environment of the metal cation in the structure and, for less trivial cases concerned with alternative coordination, "optimized" ionic radii values where metal cations can be found in different coordinations (see details in the computational procedures section).

Octahedral factors and their analogues for alternative coordinations. It was assumed that using octahedral factors ${ }^{64,65}$ in combination with the atomic scattering factor (see below) enables consideration of the possibility of cation off-centering accompanied by symmetry lowering. Alternative parameters were used in this study for the tetrahedral and dodecahedral coordinations.

Space filling parameter. Because most garnets exhibit cubic crystal structures, the impact of the space filling parameter was assumed to be important. This parameter has been assessed as:

$$
\varphi=\frac{\left(\frac{4 \pi}{3}\right)\left(\sum_{i} n_{i} R_{i}^{3}\right)}{V_{\text {cell }}}
$$

\section{Lattice volume/Li content pfu.}

Descriptors encoding materials synthesis information. Reproducibility of the cubic polymorph of garnet structures is hindered due to $\mathrm{Li}$ volatilization and contamination of $\mathrm{Al}^{3+}$ from the alumina crucible while sintering (even when the same compounds are obtained by different groups, for example by using conventional solid-state synthesis, the total conductivity values can vary greatly (see Fig. 2 and Table 1)). Moreover, because a variety of synthesis methods have been used (conventional solid-state reactions, solgel, modified sol-gel combustion, Pechini, polymerized complex, coprecipitation, microwave-assisted, etc.) with different experimental conditions that highly impact the final microstructures and, consequently, the Li-ion conductivity, it was anticipated that including the synthesis information explicitly as descriptor values could refine the model predictivity. Unfortunately, this idea cannot be mothered on authors since this, to a great extent apparent, suggestion has already been published. ${ }^{66-68}$ The given descriptor type has been represented: (i) as a sintering study alone, encoded in a 5-bit string containing values related to the experimental temperatures, sintering temperatures and times (on the assumption of a two-step process, corresponding values have been normalized to the range of 0 to 1), (ii) as an eight-bit string encompassing information on the experimental temperatures, heating and sintering regimes (here, data where the number of heating steps exceeds two were omitted; in cases where an interval of 
Table 1 Experimental details, lattice parameters, activation energies, processing and product characteristics and total conductivity values for LLNO, LLTO and LBLTO as the most investigated compounds

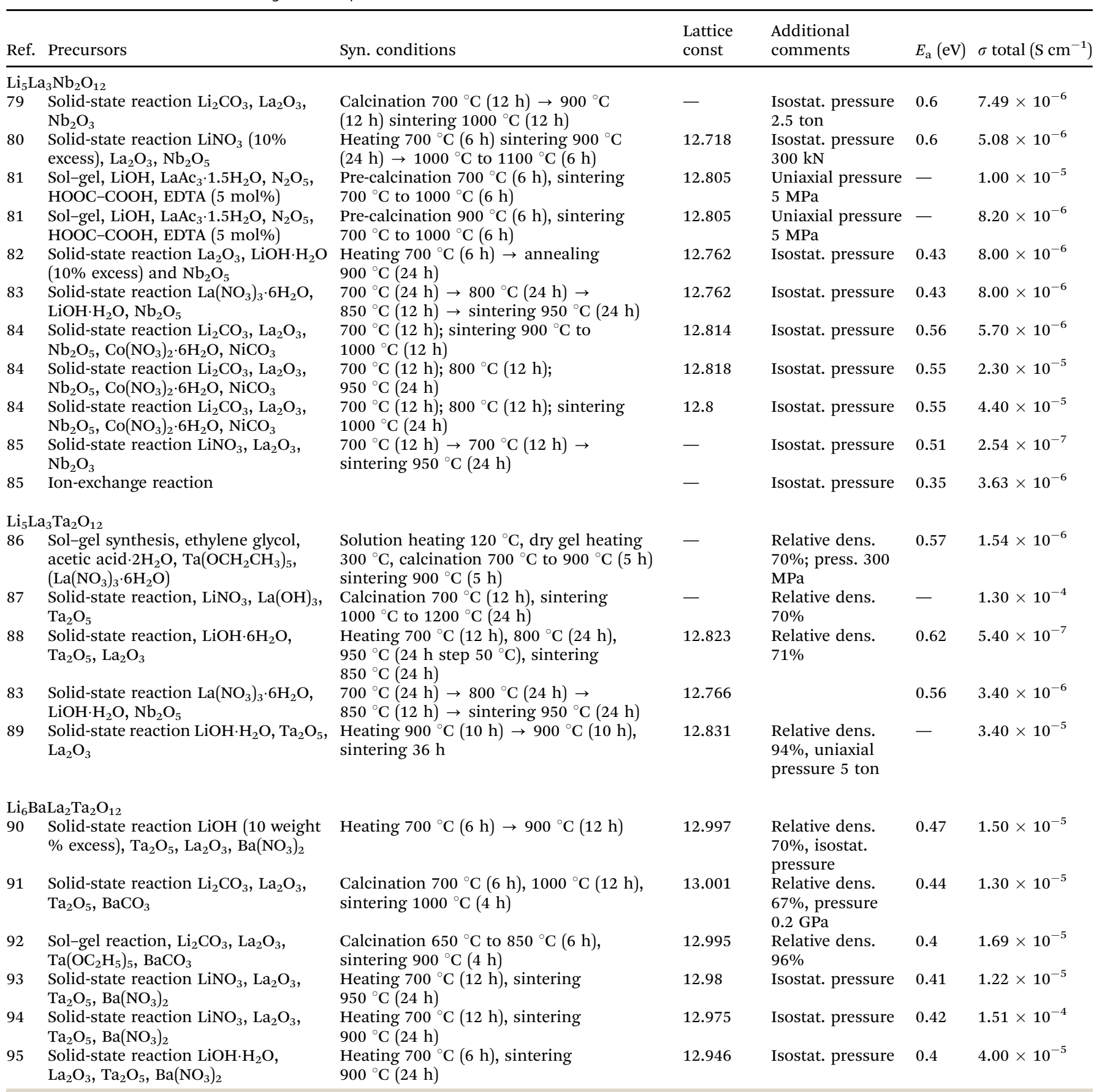

temperatures is given, the maximal value was used). In the latter case, only the solid state reactions were considered.

Atomic X-ray scattering factor is the only parameter in this study that is directly concerned with atomic electron configuration and radial electron density distribution. The corresponding values for chemical elements have been taken from ref. 69 .

\subsection{Machine learning methods}

Support vector machines (SVM) ${ }^{70}$ were used in this study for regression model development. Support vector regression (SVR) is a commonly used supervised machine learning method which is related to methods of structural risk minimization ${ }^{71}$ (arranging the trade-off between model complexity and predictive error), realizing this principle by constructing an optimal hyperplane in order to minimize a special introduced $\varepsilon$-insensitive loss function where an optimization problem is solved using the methods of quadratic programming.

The logarithm of total ionic conductivity was taken as a target predicted property. SVM models were obtained using LIBSVM software $^{72}$ with epsilon-SVR and radial basis function (RBF) 


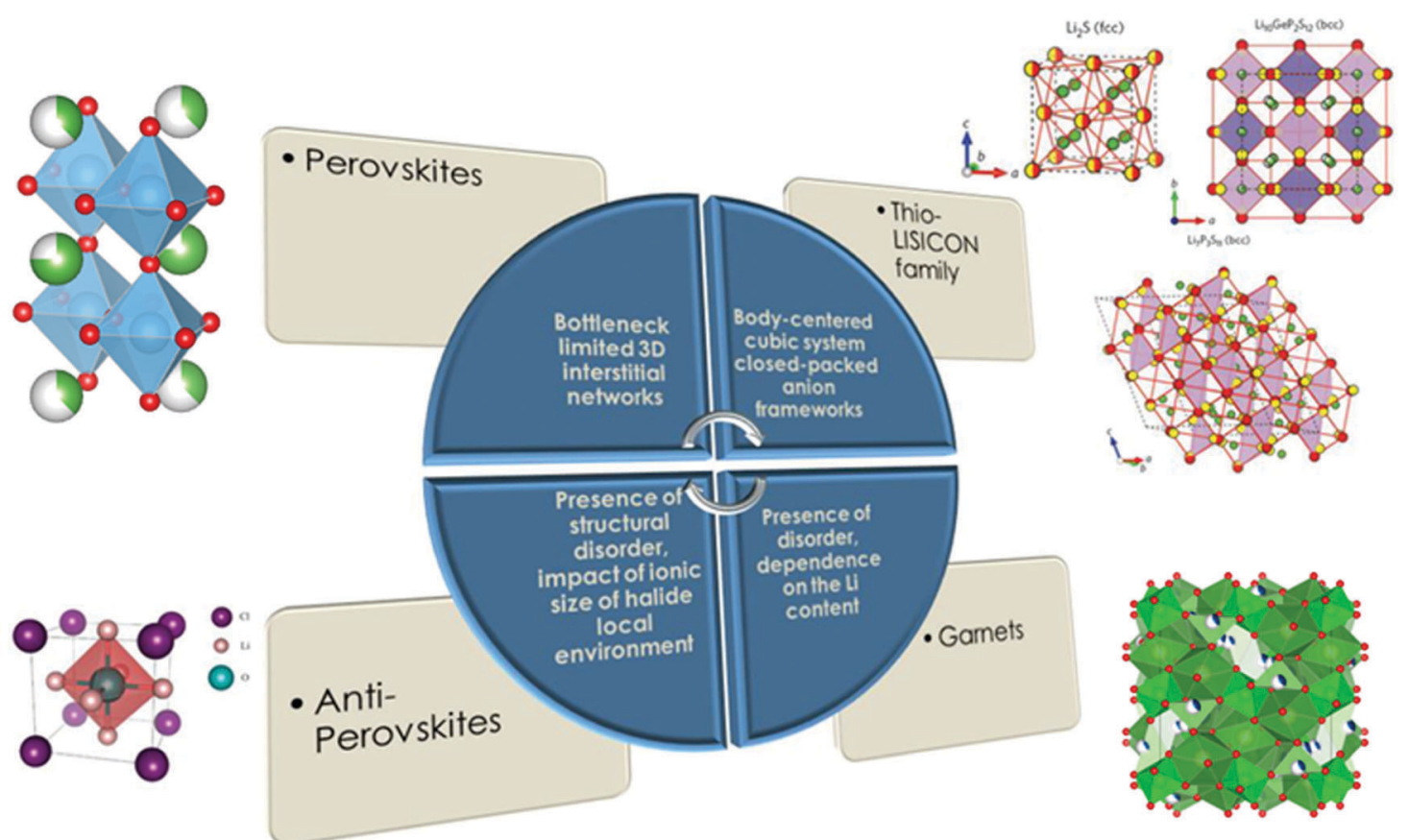

Fig. 3 Parameters designated for specific chemistries and structural types of solid electrolytes responsible for Li-ion conductivity values (part of the figure is reproduced with permission from Macmillan Publishers Ltd Nature Materials (Nat. Mater., 2015, 14, 1026-1031), copyright (2015) ${ }^{62}$ and the Royal Society of Chemistry ${ }^{63}$ ).

kernel functions. The predictive performance of each model was optimized in a grid search by varying three parameters: $C=2^{-5}, 2^{-3} \ldots 2^{15}, \varepsilon=0.0001,0.001 \ldots 10$ (internal parameters of the method) and $\gamma=2^{-15}, 2^{-13} \ldots 2^{3}$ (parameter of the RBF kernel). The models with optimized parameters providing the best SVM performance on the cross-validation tuning set (part of the training) were validated on the corresponding test set.

The predictive performances of the developed regression models were assessed using the ten-fold external cross-validation (10-CV) procedure, where the entire dataset is divided into ten nonoverlapping pairs of training and test sets of compounds (only the training set compounds are involved in model development, followed by application of the obtained models to the test set compounds in order to evaluate the predictive ability of the models). The determination coefficient $R^{2}$, root mean squared error RMSE, and mean absolute error MAE were accepted in this study as the statistical parameters assessing the ability of the models to quantitatively reproduce the experimental data. They are calculated and related as follows:

$$
\begin{gathered}
R^{2}=1-\sum\left(Y_{\text {pred }}-Y_{\text {exp }}\right)^{2} / \sum\left(Y_{\text {exp }}-\langle Y\rangle_{\exp }\right)^{2} \\
\operatorname{RMSE}=\left(\sum\left(Y_{\exp }-Y_{\text {pred }}\right)^{2} / n\right)^{1 / 2} \\
\operatorname{MAE}=\sum\left|Y_{\exp }-Y_{\text {pred }}\right| / n
\end{gathered}
$$

where $n$ is the number of data points and $Y_{\exp }$ and $Y_{\text {pred }}$ are the experimental and predicted values of the total Li ion conductivity, respectively. The difference in the RMSE and MAE values can provide additional information on the performance of the model concerning the presence of "strong" outliers in the prediction.
In this study, $t$-Distributed Stochastic Triplet Embedding ${ }^{73}$ has been used as the chemography technique. We chose this approach due to our interest in the concept that underlies this probabilistic method, which is based on a system of judgments that are close to human ones when performing a comparison of objects based on the principle "everything is relative" using similarity triplet supervision (A is more similar to B than C) in the framework of the stochastic neighbor approach. Thus, the sum of the log probabilities over all triplets of compounds in the training data is maximized:

$$
\max _{X} \sum_{\forall(i, j, l) \subseteq \tau} \log p_{i j l} ;
$$

The probabilities are defined focusing on the local similarities as follows:

$$
p_{i j l}=\frac{\left(1+\frac{x_{i}-x_{j}^{2}}{\alpha}\right)^{-\frac{\alpha+1}{2}}}{\left(1+\frac{x_{i}-x_{j}^{2}}{\alpha}\right)^{-\frac{\alpha+1}{2}}+\left(1+\frac{x_{i}-x_{l}^{2}}{\alpha}\right)^{-\frac{\alpha+1}{2}}} ;
$$

where the probability $p_{i j l}$ corresponds to probability that triplet $(i, j, l)$ satisfies to the declared rule and $\alpha$-number degrees of freedom. The resulting 2D map establishes a correspondence between the locations of the compounds in the chemical space defined by the coordinates adjusted during the training with similar compounds.

The choice of this technique finally appeared to be justifiable because it resulted in better data visualization performance compared to several alternative data visualization approaches; 
these results were omitted, as they were assumed to be excessive. The number of considered triplets $(N=10000)$ and the number of principal components $(n=4)$ of Principal Component Analysis $(\mathrm{PCA})^{74}$ that are recommended for use in this realization were optimized during the process of model development.

\subsection{Heuristic elucidation of relative site preference of $\mathrm{Al}^{3+}$ and $\mathrm{Ga}^{3+}$}

Garnet-type structure metal oxides have the general formula $\mathrm{A}_{3} \mathrm{~B}_{2}\left(\mathrm{XO}_{4}\right)_{3}$, where A, B, X - eight, six and four oxygen coordinated cation sites are known to crystallize into crystal structures in two cubic space groups ( $I a \overline{3} d$; No. 230 and $I \overline{4} 3 d)$ as well as one tetragonal space group $\left(I 4_{1} /\right.$ acd; No. 142). The tetragonal low-temperature phase exhibits low RT total conductivity values and thus cannot be considered as a material for solid state electrolytes. The cubic polymorphs can be stabilized at RT by the introduction of supervalent dopants (to date, $\mathrm{Al}^{3+}, \mathrm{Ga}^{3+}$ and $\mathrm{Fe}^{3+}$ ), which results in the formation of $\mathrm{Li}$ vacancies in the lattice to maintain general electroneutrality. The questions of site preferences and local compound coordinations for these cations remain of interest because they can be closely related to questions such as phase transitions between two observable cubic modifications in a given metal oxide type related to symmetry lowering. The experimental information on the local coordination and the site preferences is quite discordant. The most recent MAS NMR study ${ }^{51}$ using very high magnetic fields showed that $\mathrm{Al}^{3+}$ and $\mathrm{Ga}^{3+}$ have almost the same site preferences, which indicates that other parameters are responsible for the twofold efficiency of $\mathrm{Ga}^{3+}$ doping.

We decided to check if it is possible to offer insight on the relative site occupancy by adjusting the related descriptor parameters from the known experimental ionic conductivity values and analyzing the corresponding correlations. This effort appeared interesting due to the simplicity of the idea. It was believed that the agreement between the theoretical and observed experimental data could enable the use of this additional information for predicting the $\mathrm{Li}$ ion conductivities of new "virtual" compounds.

The descriptors (constitutional descriptors, Shannon ionic radii and octahedral factors) were changed in order to reflect the site occupancy preferences of the considered metal cations as well as the introduced threshold values, which can be related to the relative occupancy of tetrahedral and octahedral sites. A simple grid search was performed by adjusting the internal parameters corresponding to the threshold values of the pfu values of the doping cations $(0.01,0.05,0.1$, etc. $)$ for the cation sites (which were exceeded corresponding to changes in tetrahedral and octahedral occupancy) as well as the values corresponding to information on the relative site preferences of each doping substituent and their ionic radii values, e.g. if the amount of substituent cation A (pfu) exceeds the given threshold value, this cation begins to occupy the distorted octahedral 96h site according to the depiction of the descriptors (adjusting this value), thus corresponding to the adjustment of the relative site preference parameters (the tetrahedrally coordinated $24 d$ site was considered by default).

\section{Results and discussion}

This study addressed several aspects, such as the possibility of using the models developed here for virtual screening of new garnet-related electrolytes, using the experimental information as characteristics heavily defining the final product properties, heuristic elucidation of the relative site preferences of $\mathrm{Al}^{3+}$ and $\mathrm{Ga}^{3+}$ metal cations, etc.

Reasonable levels of predictive ability of the models have been achieved; however, some limitations remain. Using experimental details implicitly as model parameters yields unanticipated results in a given realization. Another serious limitation is the desensitization of the model by choosing one "frozen" Li ionic radius value corresponding to the tetrahedral coordination and leaving aside the information considered in ref. 75. Additional models taking into account different possible $\mathrm{Li}^{+}$coordinations and, particularly, workarounds to consider $\mathrm{Li}^{+} / \mathrm{H}^{+}$exchange if this occurs resulted in no improvement of the achieved predictive ability. Herewith, the reached predictivity provides a means of asserting the obtained models as a valid method for virtual screening of new garnet-type SSEs. Thus, the predictive ability of the regression models is represented in Fig. 4 as a function of the protocol of computations (details are presented in the Methodology (Data and descriptors) paragraph). The given values of $R^{2}$ characterizing the general model performance and the corresponding predictive error values (RMSE and MAE) are averaged over the results of 100 individual models (shuffling compounds followed by re-building of the models). As is shown, the predictive errors appear to be adequate for the requirements of models suitable for the virtual screening of new compounds. Thus, for the first data set $R^{2}$, the RMSE and MAE values are $0.778,0.372$ and 0.283 , respectively. The results of the models in predicting the external test set compounds are generally in line with this assertion. Meanwhile, significant discrepancies in the experimental and predicted $\log \sigma_{\text {tot }}$ values were observed for

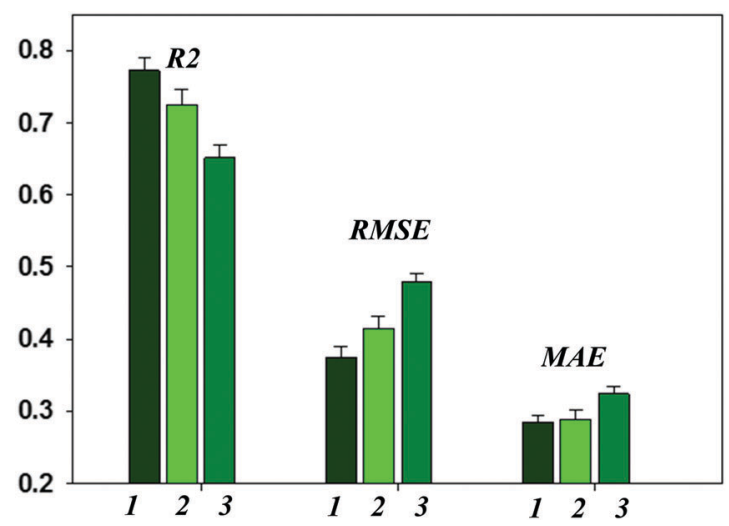

Fig. 4 Predictive performance of regression models as a function of computational details: 1 - dataset without consideration of the synthesis method and experimental conditions, formed by compounds after removal of duplicates (see details in the corresponding paragraph); 2 - dataset formed by compounds obtained via conventional solid-state reactions without consideration of experimental conditions; 3 - entire dataset (encoding reported materials synthesis and processing information as descriptor values). 
some compounds. The impact of the descriptors on the predictive ability of the models was analyzed using the SVD-USE program (developing multiple linear regression models); their contributions to the complete descriptors pool were demonstrated to be almost equal. Artificially reducing the number of descriptors emphasized the compositional descriptors (notably, tetrahedrally and dodecahedrally coordinated cations) and octahedral factors and their analogues for alternative coordinations. A general analysis and discussion of the obtained results is given below, and the prediction errors are examined.

\subsection{Experimental data analysis}

An important point that should be discussed is the intrinsic variance in the experimental data. Understanding the sources of this discrepancy in the experimental results for the same compounds obtained in different studies appears to be important, as it is related to a number of miscellaneous problems arising from the questions of synthesis route selection (the impact of the method, as in ref. 76, where, for a given example, two synthesis methods are used with controversial results for the electrochemical characteristics for the same cathode material, or the effect of the experimental conditions, as in ref. 77), to reach the reaction-by-design concept, ${ }^{78}$ the problem of reproducibility of research, the accessibility of published negative results, etc. Preliminary endeavors to explain the sometimes significant discrepancies in the experimental data have been undertaken: the experimental details, lattice constant values and activation energies for LLNO, LLTO and LBLTO, the most investigated compounds, are represented in line with their total conductivity values (Table 1). Unfortunately, the processing-property interrelation is not always evident. The encoding of experimental information in parameters thus attempting to unravel composition-processing-structure-ionic conductivity relationships for garnet-type oxides using machine learning techniques was an inception (the results are represented in one of the paragraphs below).

\subsection{Predictive ability of models}

Among the most promising garnet-type solid electrolytes are $\mathrm{Al}^{3+}, \mathrm{Ga}^{3+}$ and $\mathrm{Fe}^{3+}$-stabilized $\mathrm{Li}_{7} \mathrm{La}_{3} \mathrm{Zr}_{2} \mathrm{O}_{12}$ (LLZO). These compounds are objects of increasing attention due to their high $\mathrm{Li}$ ionic conductivities and interesting phase structure behaviors in response to doping. It was recently shown that $\mathrm{Ga}^{3+}-$ and $\mathrm{Fe}^{3+}$-stabilized LLZO can crystallize in alternative cubic space group $I \overline{4} 3 d$ (No. 220) to the cubic polymorph great while considered as the only (SG $I a \overline{3} d$; No. 230). The reasons for the phase transition and the formation of this SG are related to the site preferences of $\mathrm{Ga}^{3+}$ and $\mathrm{Fe}^{3+}$, which are possibly due to size factors. ${ }^{47}$

Here, we briefly summarize the obtained property prediction results for $\mathrm{Al}^{3+}, \mathrm{Ga}^{3+}$ and $\mathrm{Fe}^{3+}$-stabilized $\mathrm{Li}_{7} \mathrm{La}_{3} \mathrm{Zr}_{2} \mathrm{O}_{12}$ (LLZO). The total conductivity values for most of the $\mathrm{Al}^{3+}$ and $\mathrm{Ga}^{3+}$-stabilized compounds were predicted sufficiently accurately. However, the effects of $\mathrm{Al}^{3+}$ and $\mathrm{Ga}^{3+}$ co-doping remained unexplained by models. Thus, for two of three $\mathrm{Li}_{6.4} \mathrm{Al}_{0.2-x} \mathrm{Ga}_{x} \mathrm{La}_{3} \mathrm{Zr}_{2} \mathrm{O}_{12}$ compounds, ${ }^{96}$ the differences between the experimental and predicted $\log \sigma_{\text {tot }}$ values exceeded 0.5 .
As an alternative to $\mathrm{Al}^{3+}, \mathrm{Ga}^{3+}$ and $\mathrm{Fe}^{3+}$ doping, stabilized cubic LLZO polymorph is a super-valent substitution with highly charged ferroactive cations $\left(\mathrm{Ta}^{5+}, \mathrm{Nb}^{5+}, \mathrm{W}^{6+}, \mathrm{Mo}^{6+}, \mathrm{V}^{5+}\right.$ etc. $)$ on $\mathrm{Zr}^{4+}$ sites which are assumed not to hinder the Li ion diffusion pathways (unlike tetrahedral site doping) and, hence, can be considered as more efficient. Here, one can attribute the difficulty of prediction of the compounds to the simultaneous presence of $\mathrm{Nb}^{5+}$ and $\mathrm{V}^{5+}$ cations in the structure. ${ }^{97}$ The disagreement between the experimental and predicted values was acceptable $\left(\sim 0.2\right.$ in $\left.\log \sigma_{\text {tot }}\right)$ for $\mathrm{Li}_{5} \mathrm{La}_{3} \mathrm{Nb}_{2-x} \mathrm{~V}_{x} \mathrm{O}_{12}(x=0.05,0.1)$ and steeply increased for $\mathrm{Li}_{5} \mathrm{La}_{3} \mathrm{Nb}_{2-x} \mathrm{~V}_{x} \mathrm{O}_{12}(x=0.15,0.2,0.25)$. Formation of secondary phases has been observed for $\mathrm{Li}_{5} \mathrm{La}_{3} \mathrm{Nb}_{2-x} \mathrm{~V}_{x} \mathrm{O}_{12}(x=0.2,0.25)$.

The predictions for $\mathrm{Li}_{7} \mathrm{La}_{3} \mathrm{Hf}_{2} \mathrm{O}_{12}$ compounds ${ }^{98}$ were not sufficiently accurate, possibly due to discrepancies in the experimental total conductivity values published in ref. 98 and 99.

The relatively poor conductivity prediction for $\mathrm{Li}_{6.8} \mathrm{La}_{3} \mathrm{Zr}_{1.8^{-}}$ $\mathrm{Sb}_{0.2} \mathrm{O}_{12}$ may be related to the "cliff" property that appeared in the experimental conductivity values from ref. 100. This observation can be related with discrepancy in the relative density of this sample as well as in the difference in the total conductivity assessment where this compound was the only for which impedance plot was resolved into bulk, grain boundary and electrode resistance, for other compounds total conductivity value was evaluated as the inverse of the resistivity.

Finally, the predicted conductivity for $\mathrm{Li}_{5} \mathrm{La}_{3} \mathrm{Ta}_{2} \mathrm{O}_{12}$ from ref. 101 was very different from its corresponding experimental value.

The total conductivities for Ba-substituted LLT compounds $\left(\mathrm{Li}_{5+x} \mathrm{BaLa}_{2} \mathrm{Ta}_{2} \mathrm{O}_{11.5+0.5 x}\right)^{102}$ were systematically underestimated by models that included the difference in the experimental temperatures, the oxygen nonstoichiometry of these compounds or their instability to moisture. ${ }^{103}$ In contrast, the total conductivities of $\mathrm{Gd}^{3+}$-substituted $\mathrm{LLN}^{79}$ were overestimated by the models, except those for LLN-Gd60 (impurity phases were observed for this particular compound). The incorrect predictions for these compounds as well as for supervalent $\left(\mathrm{Ce}^{4+}\right)$-substituted LLZO $\mathrm{Li}_{6.6} \mathrm{La}_{2.6} \mathrm{Ce}_{0.4} \mathrm{Zr}_{2} \mathrm{O}_{12}{ }^{104}$ remain unexplained.

\subsection{Heuristic elucidation of the relative site preferences of $\mathrm{Al}^{3+}$ and $\mathrm{Ga}^{3+}$ cations}

Here, some ambiguous results are discussed. This ambiguity is a result of both the simplified method offering insight on the relative site occupancies and adjusting the parameters of the related descriptors using known experimental ionic conductivity values (the correspondence between the predicted and experimental values was considered as a congruence criterion) followed by analyzing the corresponding correlations with predictions, as well as the character of the results obtained.

The greatest consistency with experimental total conductivity values was obtained as a result of a grid search performed with the following parameters:

(i) If the amount of substituent cation A (pfu) exceeds the threshold value of 0.1 for $\mathrm{Ga}^{3+}$ and 0.01 for $\mathrm{Al}^{3+}$ (almost all the compounds), the tetrahedrally coordinated $24 d$ sites 0.1 and 0.2 are occupied, respectively, assuming that 0.9 and 0.8 of $\mathrm{Ga}^{3+}$ and $\mathrm{Al}^{3+}$ are accommodated by the octahedrally coordinated $96 h$ site. 


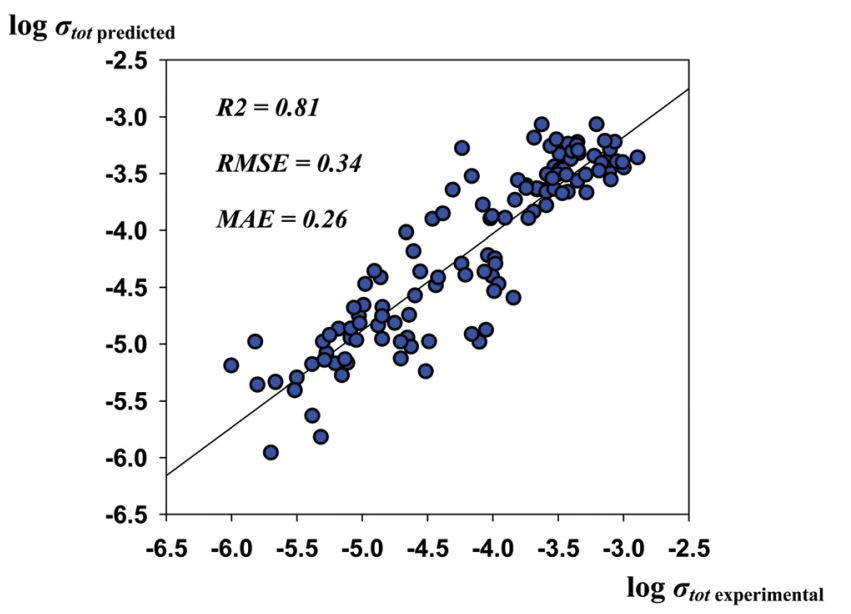

Fig. 5 The predicted vs. experimental $\log \sigma_{\text {tot }}$ values for the optimized "best" model during heuristic elucidation of the relative site preferences of $\mathrm{Al}^{3+}$ and $\mathrm{Ga}^{3+}$ cations.

(ii) Increasing the threshold value for $\mathrm{Al}^{3+}$ to 0.1 blurred the occupancies of $\mathrm{Ga}^{3+}$ and $\mathrm{Al}^{3+}$ to the ranges of 0.1 to 0.4 and 0.2 to 0.5 , respectively.

(iii) Further increasing the threshold for $\mathrm{Ga}^{3+}$ resulted in changes of the occupation of the tetrahedrally coordinated $24 d$ sites to 0.7 and 0.5 for $\mathrm{Ga}^{3+}$ and $\mathrm{Al}^{3+}$, respectively.

The results presented here that were not confirmed to be in agreement with experimental observation (although the published experimental data on the local coordination and the site preferences are quite discordant) should still be discussed, as they led to improvement of the predictive performance of the models. Thus, the $R^{2}$, RMSE and MAE values for the optimized model are as high as $0.81,0.34$, and 0.26 , respectively. The predicted $v s$. experimental $\log \sigma_{\text {tot }}$ values are represented in Fig. 5.

The evaluation of statistical relevance of the observed improvement of the predictive ability of the models is not sufficiently correct. First, a different descriptor set was used for model development; second, it is hindered by the number of $\mathrm{Al}^{3+}$ and $\mathrm{Ga}^{3+}$-stabilized LLZO compounds available. However, the analysis of the property prediction revealed a significant improvement in the predictive ability of the model. First, the effects of $\mathrm{Al}^{3+}$ and $\mathrm{Ga}^{3+}$ co-doping, which remained unexplained in previous calculations, appeared to be described precisely here. Thus, finally, no outlier-by-prediction $\mathrm{Al}^{3+}$ and $\mathrm{Ga}^{3+}$-doped compounds were observed. Second, the general predictive ability of the models was increased.

\subsection{Using experimental information as descriptors}

A description of the descriptor types is given in the data and descriptors paragraph. By analyzing the data, one can see that a variety of synthesis methods have been used for sample preparation (conventional solid-state reactions, sol-gel, modified sol-gel combustion, Pechini, polymerized complex, co-precipitation, microwave assisted, etc.) with different experimental conditions that highly impact the final microstructure and, consequently, the Li-ion conductivity. Additionally, even for compounds obtained using the same experimental synthesis method, one can see that the evaluated $\mathrm{Li}$ ion total conductivity value varied in a wide range up to several orders of magnitude (see Table 1 and Fig. 2). Therefore, the concept of using the synthesis information explicitly as descriptors refining the predictivity of the model was itself feasible. However, its implementation appeared to be unsatisfying. The case where only the sintering step was encoded resulted in models with moderate predictive performance (at least, for regression models), as shown in Fig. 4. Similarly, distinguishing the data issued from the solid-state reactions and encoding most of the processing history (if possible in principle ${ }^{105}$ ) did not improve the total conductivity predictions. Additionally, its apparent shortcomings include: first, the non-optimal method chosen to encode information as descriptor values; second, the disparity between the number of compounds obtained using conventional solid-state reactions and all other approaches en bloc; and finally, the consideration of similar reported materials synthesis and processing information for compounds with different property values (Table 1 ).

\subsection{Other computational protocols}

Involving space filling parameter as descriptors' type to models' development provides no improvement of model predictive ability that is in a combination with reduced number of compounds in the data set (as a result of missing structural data in a number of studies) made its application inexpedient. Fig. 6 represents the Li ion conductivity and activation energies as a function of the normalized lattice volume parameter, demonstrating a similar situation where using lattice volume value as a descriptor parameter despite observed correlations also appeared to be unfeasible.

"Averaged property" computations were performed as a shortcut for the data selection procedure in cases where it was necessary to choose one compound among many. Ideally, it has to be performed entirely by the expert opinion which is not always possible due to the coincident description of the published experimental data. Thus, this study can be considered as some sort of the compromise between the undertaken efforts of such data evaluation and final quite rustic implementation. The results of the performed procedure demonstrate similar predictive performance to the first type of model computation.

We additionally attempted to distinguish compounds that can be potentially instable to moisture. Thus, the possible instability of garnet structures to moisture has been related to accommodation of the tetrahedral and octahedral sites by $\mathrm{Li}^{+}$. Recently, it was shown that increasing $\mathrm{Li}$ content results in the re-distribution of $\mathrm{Li}$ ions among tetrahedrally coordinated $24 d$ sites and octahedrally coordinated $96 h$ sites, increasing accommodation of the latter. ${ }^{75}$ It was also reported that compounds with high Li content can be especially sensitive to moisture. Conjoining the given observations, we considered this by means of corresponding adjustment of the descriptor values. The obtained results show no improvement in the predictive performance of the models, which can be interpretable as superfluous information (the described behavior is already reflected in a roundabout way in the compositional descriptors, which provide one of the greatest contributions to the models), as an infeasibility to 

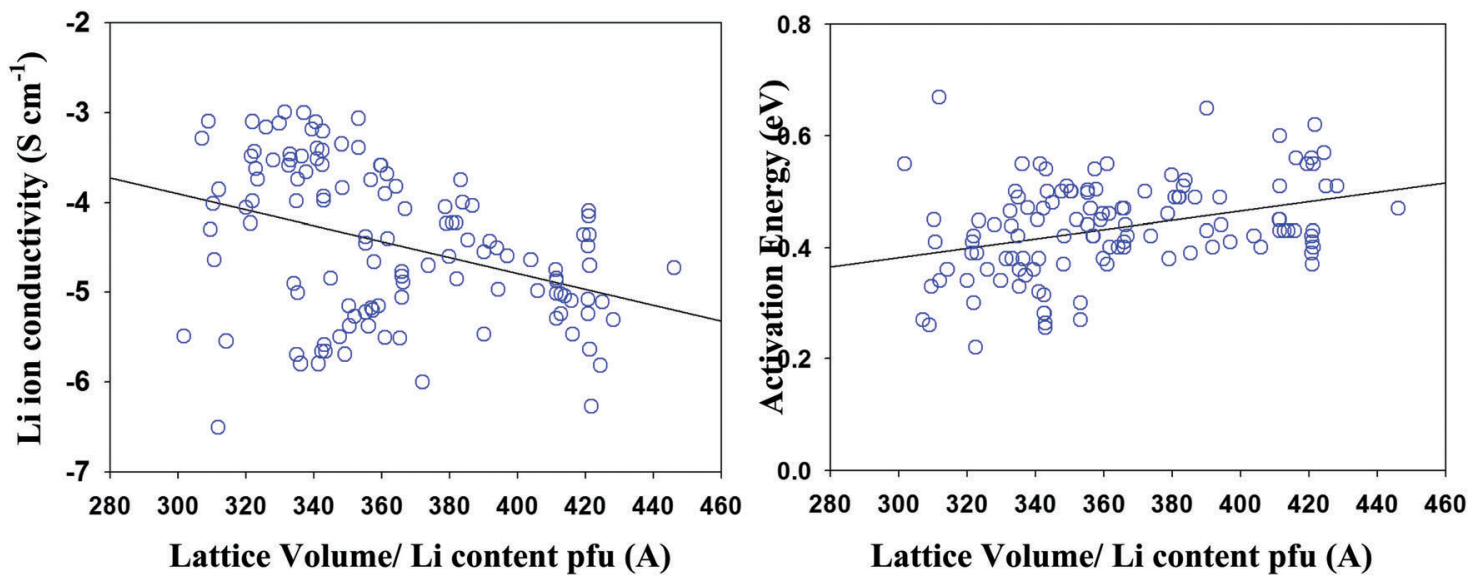

Fig. 6 Li ion conductivity and activation energy as a function of lattice volume.

consider complex problems using the given approach, or, finally, as further indication of the lack of impact of $\mathrm{Li}^{+} / \mathrm{H}^{+}$ exchange on the total conductivity values.

\subsection{Prediction of the external test set}

The external test set encompasses all $\mathrm{Ga}^{3+}$-substituted compounds (with known experimental values of total ionic conductivity) detached from the initial data set (these compounds were preliminarily excluded from the training data used for development of the models), $\mathrm{Fe}^{3+}$-substituted compounds, ${ }^{47}$ and several out-of-bag compounds not included in the initial data set ${ }^{77,106-109}$ as well as the suggested "virtual" garnet-type compounds substituted with $\mathrm{Zn}^{2+}, \mathrm{Ni}^{2+}, \mathrm{Cu}^{2+}, \mathrm{Sc}^{3+}, \mathrm{Cr}^{3+}$, and $\mathrm{Rb}^{+}$cations. Here, $\mathrm{Ga}^{3+}$-substituted compounds were detached from the initial data in order to check if the developed models have predictive ability for compounds containing "new" dopants different from those in the training set.

The results of the external test set predictions are represented in Table 2. It should be pointed out that for the suggested "virtual" compounds, high predicted total conductivity values alone are not sufficient, as these compounds may exhibit also electronic conductivity, which makes them infeasible for application as materials for solid state electrolytes.

\subsection{Visualization of the chemical space of solid-state electrolytes}

Visualization of the chemical space of garnet-type solid electrolytes was performed using $t$-stochastic triplet embedding ( $t$-STE) (Fig. 7). Each point in the obtained map is an individual compound; the color corresponds to the $\log \sigma_{\text {tot }}$ value. The external test set compounds are represented by black circles. One can see that almost all of these compounds are situated in the area corresponding to high $\log \sigma_{\text {tot }}$ values. The distribution of the compounds is in agreement with the SVR conductivity prediction. The reasonable separation of the areas of chemical space in accordance with the $\log \sigma_{\text {tot }}$ value of the compounds confirms the appropriateness of the choice of descriptors for elucidating composition-structure-property relationships because $t$-STE is related to unsupervised techniques where the information
Table 2 Validation of the predictive ability of the models for virtual screening: experimental and predicted values of total conductivities (log $\left.\sigma_{\text {tot }}\right)$ for the "virtual" and synthesized compounds of the external test set

\begin{tabular}{|c|c|c|}
\hline Compound name & $\begin{array}{l}\text { Experimental } \\
\log \sigma_{\text {tot }}\left(\mathrm{S} \mathrm{cm}^{-1}\right)\end{array}$ & $\begin{array}{l}\text { Predicted } \log \sigma_{\text {tot }} \\
\left(\mathrm{S} \mathrm{cm}^{-1}\right)\end{array}$ \\
\hline $\mathrm{Li}_{6.4} \mathrm{Ga}_{0.2} \mathrm{La}_{3} \mathrm{Zr}_{2} \mathrm{O}_{12}$ & -3.40 & -3.25 \\
\hline $\mathrm{Li}_{6.15} \mathrm{La}_{3} \mathrm{Zr}_{1.75} \mathrm{Ta}_{0.25} \mathrm{Ga}_{0.2} \mathrm{O}_{12}$ & -3.39 & -3.37 \\
\hline $\mathrm{Li}_{6.55} \mathrm{La}_{3} \mathrm{Zr}_{2} \mathrm{Ga}_{0.15} \mathrm{O}_{12}$ & -2.89 & -3.18 \\
\hline $\mathrm{Li}_{6.4} \mathrm{La}_{3} \mathrm{Zr}_{2} \mathrm{Ga}_{0.2} \mathrm{O}_{12}$ & -3.05 & -3.25 \\
\hline $\mathrm{Li}_{6.1} \mathrm{La}_{3} \mathrm{Zr}_{2} \mathrm{Ga}_{0.3} \mathrm{O}_{12}$ & -4.15 & -3.42 \\
\hline $\mathrm{Li}_{5.5} \mathrm{La}_{3} \mathrm{Zr}_{2} \mathrm{Ga}_{0.5} \mathrm{O}_{12}$ & -4.00 & -3.89 \\
\hline $\mathrm{Li}_{6.4} \mathrm{Al}_{0.15} \mathrm{Ga}_{0.05} \mathrm{La}_{3} \mathrm{Zr}_{2} \mathrm{O}_{12}$ & -3.42 & -3.71 \\
\hline $\mathrm{Li}_{6.4} \mathrm{Al}_{0.1} \mathrm{Ga}_{0.1} \mathrm{La}_{3} \mathrm{Zr}_{2} \mathrm{O}_{12}$ & -3.20 & -3.69 \\
\hline $\mathrm{Li}_{6.4} \mathrm{Al}_{0.05} \mathrm{Ga}_{0.15} \mathrm{La}_{3} \mathrm{Zr}_{2} \mathrm{O}_{12}$ & -3.97 & -3.66 \\
\hline $\mathrm{Li}_{6.4} \mathrm{Ga}_{0.2} \mathrm{La}_{3} \mathrm{Zr}_{2} \mathrm{O}_{12}$ & -3.93 & -3.25 \\
\hline $\mathrm{Li}_{6.25} \mathrm{La}_{3} \mathrm{Zr}_{2} \mathrm{Ga}_{0.25} \mathrm{O}_{12}$ & -3.46 & -3.33 \\
\hline $\mathrm{Li}_{6.7} \mathrm{Fe}_{0.1} \mathrm{La}_{3} \mathrm{Zr}_{2} \mathrm{O}_{12}$ & & -3.16 \\
\hline $\mathrm{Li}_{6.46} \mathrm{Fe}_{0.18} \mathrm{La}_{3} \mathrm{Zr}_{2} \mathrm{O}_{12}$ & & -3.25 \\
\hline $\mathrm{Li}_{6.52} \mathrm{Fe}_{0.16} \mathrm{La}_{3} \mathrm{Zr}_{2} \mathrm{O}_{12}$ & & -3.23 \\
\hline $\mathrm{Li}_{6.4} \mathrm{Fe}_{0.2} \mathrm{La}_{3} \mathrm{Zr}_{2} \mathrm{O}_{12}$ & & -3.28 \\
\hline $\mathrm{Li}_{6.25} \mathrm{Fe}_{0.25} \mathrm{La}_{3} \mathrm{Zr}_{2} \mathrm{O}_{12}$ & & -3.36 \\
\hline $\mathrm{Li}_{6.1} \mathrm{Fe}_{0.3} \mathrm{La}_{3} \mathrm{Zr}_{2} \mathrm{O}_{12}$ & & -3.45 \\
\hline $\mathrm{Li}_{6.7} \mathrm{Cr}_{0.1} \mathrm{La}_{3} \mathrm{Zr}_{2} \mathrm{O}_{12}$ & & -3.22 \\
\hline $\mathrm{Li}_{6.7} \mathrm{Ni}_{0.1} \mathrm{La}_{3} \mathrm{Zr}_{2} \mathrm{O}_{12}$ & & -3.10 \\
\hline $\mathrm{Li}_{6.7} \mathrm{Cu}_{0.1} \mathrm{La}_{3} \mathrm{Zr}_{2} \mathrm{O}_{12}$ & & -3.84 \\
\hline $\mathrm{Li}_{7.25} \mathrm{La}_{2.875} \mathrm{Rb}_{0.125} \mathrm{Zr}_{2} \mathrm{O}_{12}$ & & -3.23 \\
\hline $\mathrm{Li}_{7.5} \mathrm{La}_{2.75} \mathrm{Rb}_{0.25} \mathrm{Zr}_{2} \mathrm{O}_{12}$ & & -3.41 \\
\hline $\mathrm{Li}_{7.75} \mathrm{La}_{2.62} \mathrm{Rb}_{0.375} \mathrm{Zr}_{2} \mathrm{O}_{12}$ & & -3.62 \\
\hline $\mathrm{Li}_{6.7} \mathrm{La}_{3} \mathrm{Zr}_{1.9} \mathrm{Zn}_{0.1} \mathrm{O}_{12}$ & & -3.30 \\
\hline $\mathrm{Li}_{6.35} \mathrm{La}_{3} \mathrm{Nb}_{1.375} \mathrm{Sc}_{0.625} \mathrm{O}_{12}$ & -3.86 & -3.74 \\
\hline $\mathrm{Li}_{6.52} \mathrm{Al}_{0.08} \mathrm{La}_{3} \mathrm{Zr}_{1.75} \mathrm{Ta}_{0.25} \mathrm{O}_{12}$ & -3.11 & -3.26 \\
\hline $\mathrm{Li}_{6.5} \mathrm{La}_{3} \mathrm{Sn}_{1.5} \mathrm{Ta}_{0.5} \mathrm{O}_{12}$ & -3.62 & -3.78 \\
\hline $\mathrm{Li}_{6.65} \mathrm{Ga}_{0.15} \mathrm{La}_{3} \mathrm{Zr}_{1.9} \mathrm{Sc}_{0.1} \mathrm{O}_{12}$ & -2.74 & -2.90 \\
\hline $\mathrm{Li}_{6.9} \mathrm{La}_{3} \mathrm{Zr}_{1.9} \mathrm{Bi}_{0.1} \mathrm{O}_{12}$ & & -3.36 \\
\hline $\mathrm{Li}_{6.6} \mathrm{La}_{3} \mathrm{Zr}_{1.8} \mathrm{Mo}_{0.2} \mathrm{O}_{12}$ & -3.29 & -3.31 \\
\hline
\end{tabular}

on the property value is not involved in the process of the model development itself and is engaged only for final data visualization of the already obtained model if needed. One can see that among the proposed compounds, only $\mathrm{Rb}^{+}$-substituted LLZO is projected to the areas of the low total conductivity space. All the other "virtual" compounds form a distinct cluster joined with the $\mathrm{Ga}^{3+}$ and $\mathrm{Al}^{3+}$-stabilized LLZO compounds.

Fig. 8 corresponds to the model involving experimental information as an additional descriptor pool and reflecting 


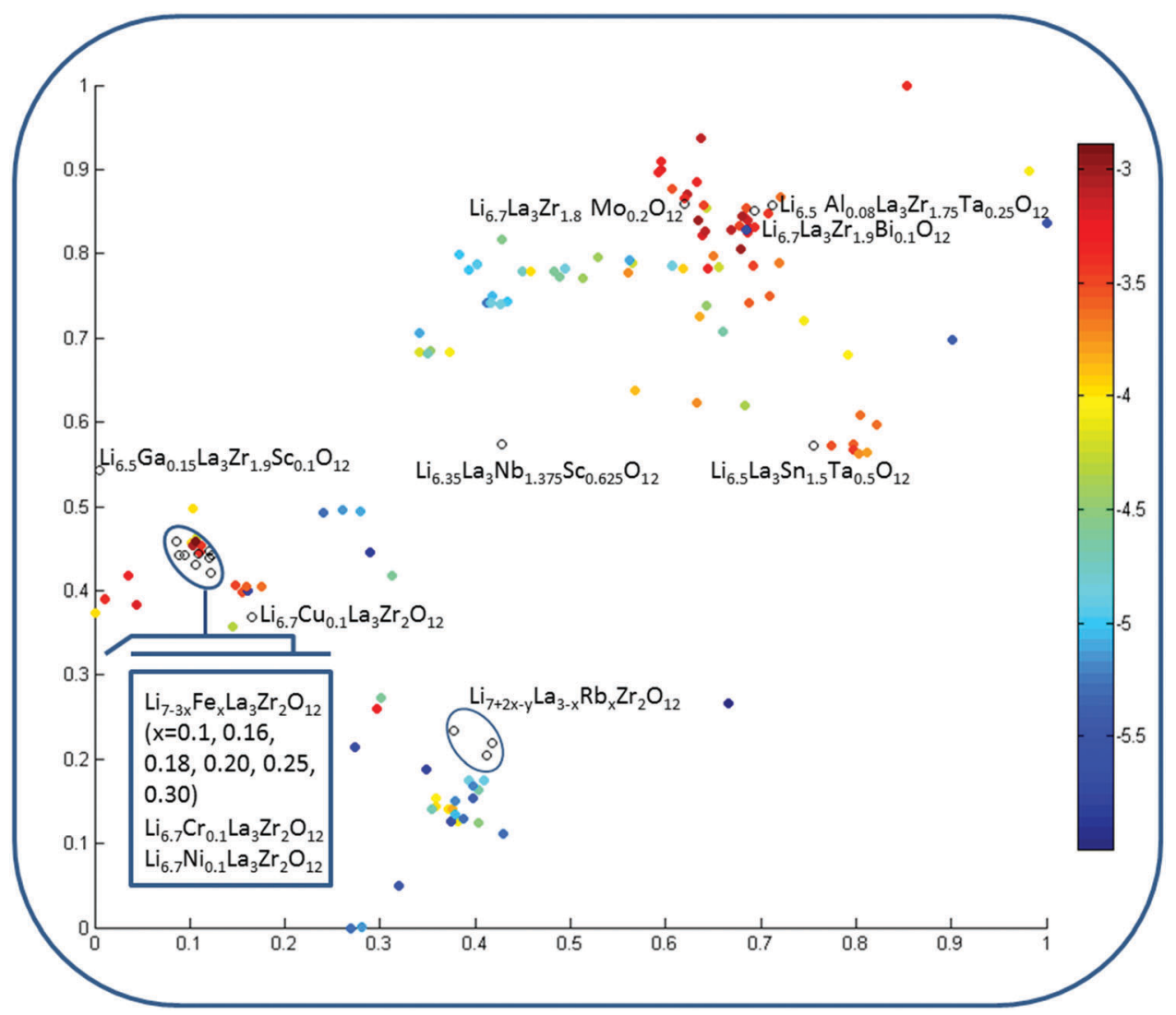

Fig. 7 Visualization of the chemical space of garnet-type solid electrolytes (dataset 1; for more details on this, please see the Data and descriptors paragraph) using $t$-stochastic triplet embedding. Each point is an individual compound where the color corresponds to the log $\sigma_{\text {tot }}$ value; external test set compounds are represented by black circles.

the analysis from the viewpoint of the impact of these parameters on the property space. First of all, one can observe the significantly lowest discrepancy for the data visualization models among the considered property spaces defined by the descriptors in use compared with the regression models, where this difference was substantial. Second, one can see the relatively reduced area corresponding to high $\log \sigma_{\text {tot }}$ values.

Two cases for three descriptor pools are considered: two types of normalization where (i) parameters responsible for the materials synthesis information were scaled to union variance in order to avoid the dominant contribution of any or (ii) re-weighted (by multiplying by 2) parameters for (a) virtual compounds that have been generated as synthesized by conventional one-step solid state reactions (sintering temperature $1100{ }^{\circ} \mathrm{C}$; time $36 \mathrm{~h}$; represented as black mark points in the figure); (b) the same data obtained via two-stage sintering processes (the sintering conditions have been taken from published studies - sintering temperature $900{ }^{\circ} \mathrm{C} / 1100{ }^{\circ} \mathrm{C}$; time $24 / 6 \mathrm{~h}$; labeled by red guide-marks); (c) finally, the descriptor pool corresponding to sol-gel synthesis with experimental conditions conforming with published studies (sintering temperature $1200{ }^{\circ} \mathrm{C}$; time $36 \mathrm{~h}$; compounds represented as blue circles), i.e. the same candidate compounds in the map are distinguished by different color coding related to the synthesis conditions. Results of the second normalization scheme are given in Fig. 8 because they appeared to be more meaningful (in the models using the descriptor scaling to union variance scheme, the weight of the experimental information is minimized).

To sum up, reasonable levels of predictive ability of the models have been achieved. The predictive errors (RMSE and MAE) are comparable with the variance in the total conductivities for the same compounds extracted from different publications. The observed limitations of the predictive ability of the models can be concerned with different aspects. Obviously, one of the most valuable stages is the selection of descriptors. Here, we have used a simple and even naive approach that is based mostly on "geometrical" insights into the problem. However, the predictive performance of the developed models argues that they were sufficiently successful that it would be reasonable to extend these efforts to answer a number of pivotal questions that were not addressed here. Another serious limitation of the developed models is related to the ionic radii of Li. Thus, the problem considered in ref. 75 was ignored here and the models were desensitized by choosing one frozen ionic radius value corresponding to tetrahedral coordination. Moreover, using the information in ref. 75 in test computations had no impact on the predictive ability of the models.

Additionally, the collected data has not been used sufficiently. Thus, information on the activation energy, pressure, use of the hot pressure approach, formation of secondary phases, 


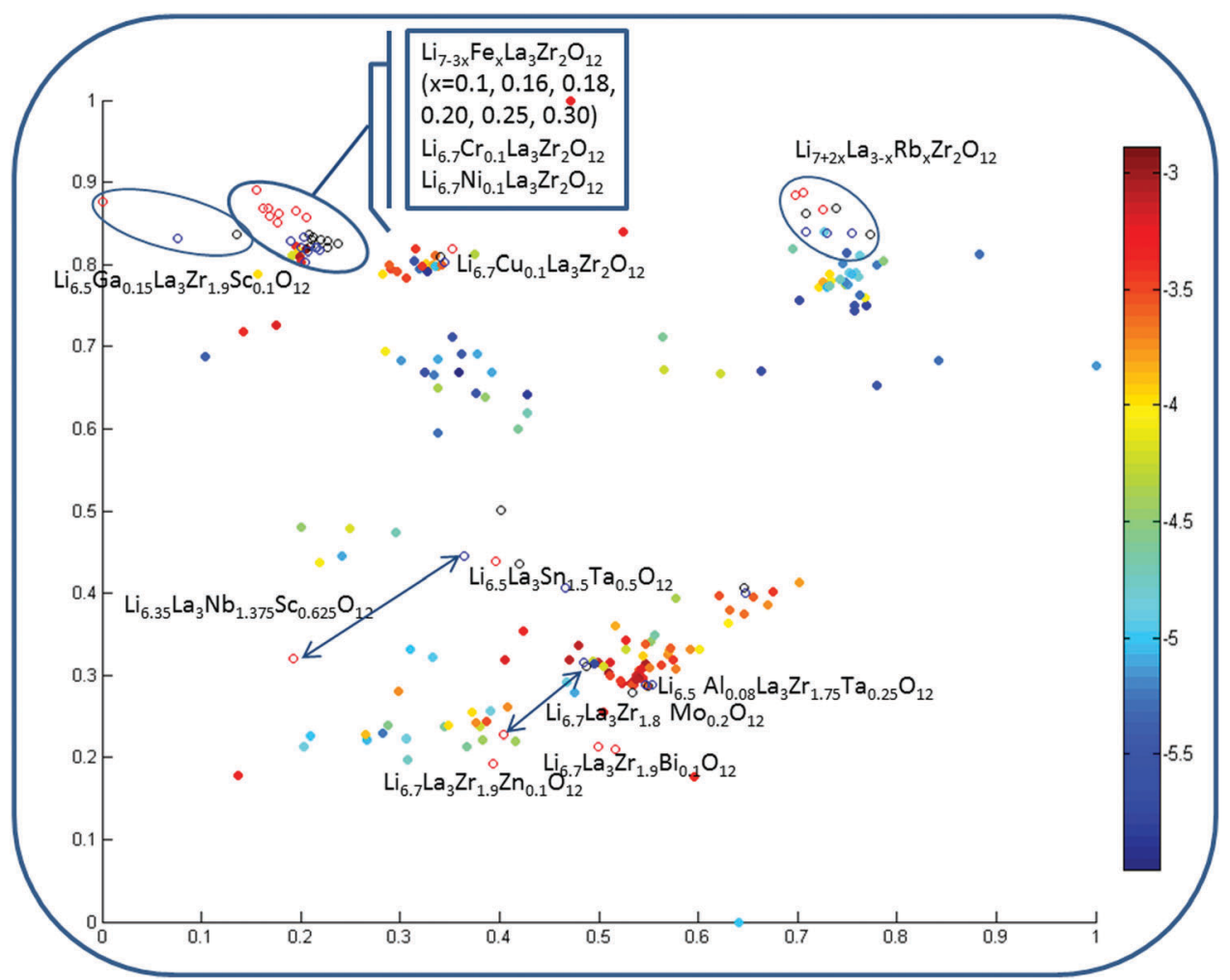

Fig. 8 Visualization of the chemical space of garnet-type solid electrolytes using $t$-stochastic triplet embedding including the experimental information as an additional descriptor pool. Each point is an individual compound, where the filling color corresponds to the log $\sigma_{\text {tot }}$ value; the candidate compounds of the external test set are distinguished by different color coding related to the synthesis conditions: (a) virtual compounds that have been generated via synthesis by conventional one-step solid state reactions (sintering temperature $1100{ }^{\circ} \mathrm{C}$; time $36 \mathrm{~h}$; represented as black mark points in the figure); (b) the same data obtained via two-stage sintering processes (the sintering conditions have been taken from published studies - sintering temperature $900^{\circ} \mathrm{C} / 1100^{\circ} \mathrm{C}$; time $24 / 6 \mathrm{~h}$; labeled by red guide marks); (c) finally, a descriptor pool corresponding to sol-gel synthesis with experimental conditions conforming with published studies (sintering temperature $1200{ }^{\circ} \mathrm{C}$; time $36 \mathrm{~h}$; compounds represented as blue circles).

and precursors used as well as the relative densities of the obtained samples have not been included in this study.

\section{Conclusions}

Several types of parameters related to different categories have been used as descriptors to develop a model to identify the descriptors that are responsible for high Li-ion conductivity in garnet-structured oxides; most of the identified parameters were geometry-based and stemmed from the interrelations of constituent element radii with geometric principles of ion packing.

The $\mathrm{Li}$ ion transport characteristics of garnet-structured oxides were analyzed combining regression analysis by support vector regression (SVR), thus unraveling the compositionstructure-ionic conductivity relationships and surveying garnetrelated structures for promising compositions with $t$-stochastic triplet embedding ( $t$-STE), which is related to the group of approaches known in computer-aided molecular design as chemography or cartography methods and which circumscribes the materials space of solid electrolytes; this is attractive for virtual screening. A reasonable level of predictive ability of the models was achieved (the statistical parameters $R^{2}$, RMSE and
MAE of the SVR model are as high as $0.778,0.372$ and 0.283 , respectively). The predictive errors (RMSE and MAE) are comparable with the variance in the total conductivities for the same compounds extracted from different publications. The observed limitations of the predictive ability of the models can involve different aspects, such as the choice of descriptors or the intrinsic variance in the experimental data. The models obtained by $t$-STE demonstrate clear allocation of the areas of chemical space in accordance with the $\log \sigma_{\text {tot }}$ value of the compounds; this confirms the appropriateness of the chosen descriptors for elucidating composition-structure-property relationships and enables an intuitively understandable method of structure optimization. Both models were used to evaluate the $\log \sigma_{\text {tot }}$ values for the candidate compounds recommended for synthesis.

Heuristic elucidation of the relative site preferences of $\mathrm{Al}^{3+}$ and $\mathrm{Ga}^{3+}$ cations was attempted. The character of the obtained results has been discussed. We attempted to distinguish compounds that can be potentially instable to moisture. The possible instability of garnet structures to moisture was related to tetrahedral and octahedral site accommodation by $\mathrm{Li}^{+}$. Unfortunately, the results obtained are not sufficient for any conclusions.

Several candidate compounds have been recommended for synthesis as potential solid state electrolyte materials. 


\section{Acknowledgements}

The authors are grateful to the Russian Foundation for Basic Research (Project No. 17-03-00835) for their support. NK acknowledges Dr Vitaly Solov'ev and Dr E. V. Makhonina for their helpful comments.

\section{References}

1 J. F. M. Oudenhoven, L. Baggetto and P. H. L. Notten, $A d v$. Energy Mater., 2011, 1, 10-33.

2 J. B. Goodenough and P. Singh, J. Electrochem. Soc., 2015, 162, A2387-A2392.

3 J. Jensen and F. C. Krebs, Adv. Mater., 2014, 26, 7231-7234. 4 X. Xia, Z. Ku, D. Zhou, Y. Zhong, Y. Zhang, Y. Wang, M. J. Huang, J. Tu and H. J. Fan, Mater. Horiz., 2016, 3, 588-595.

5 J. C. Bachman, S. Muy, A. Grimaud, H.-H. Chang, N. Pour, S. F. Lux, O. Paschos, F. Maglia, S. Lupart, P. Lamp, L. Giordano and Y. Shao-Horn, Chem. Rev., 2016, 116, 140-162.

6 R. Chen, W. Qu, X. Guo, L. Li and F. Wu, Mater. Horiz., 2016, 3, 487-516.

7 P. Knauth, Solid State Ionics, 2009, 180, 911-916.

8 E. Quartarone and P. Mustarelli, Chem. Soc. Rev., 2011, 40, 2525-2540.

9 Y. Ren, K. Chen, R. Chen, T. Liu, Y. Zhang and C.-W. Nan, J. Am. Ceram. Soc., 2015, 98, 3603-3623.

10 S. Stramare, V. Thangadurai and W. Weppner, Chem. Mater., 2003, 15, 3974-3990.

11 V. Thangadurai, S. Narayanan and D. Pinzaru, Chem. Soc. Rev., 2014, 43, 4714-4727.

12 V. Thangadurai, D. Pinzaru, S. Narayanan and A. K. Baral, J. Phys. Lett., 2015, 6, 292-299.

13 P. Dey, J. Bible, S. Datta, S. Broderick, J. Jasinski, M. Sunkara, M. Menon and K. Rajan, Comput. Mater. Sci., 2014, 83, 185-195.

14 K. Fujimura, A. Seko, Y. Koyama, A. Kuwabara, I. Kishida, K. Shitara, C. A. J. Fisher, H. Moriwake and I. Tanaka, $A d v$. Energy Mater., 2013, 3, 980-985.

15 R. Jalem, T. Aoyama, M. Nakayama and M. Nogami, Chem. Mater., 2012, 24, 1357-1364.

16 R. Jalem, M. Kimura, M. Nakayama and T. Kasuga, J. Chem. Inf. Model., 2015, 55, 1158-1168.

17 R. Jalem, M. Nakayama and T. Kasuga, J. Mater. Chem. A, 2014, 2, 720-734.

18 M. S. Park, I. Park, Y.-S. Kang, D. Im and S.-G. Doo, Phys. Chem. Chem. Phys., 2016, 18, 26807-26815.

19 E. O. Pyzer-Knapp, K. Li and A. Aspuru-Guzik, Adv. Funct. Mater., 2015, 25, 6495-6502.

20 E. O. Pyzer-Knapp, G. N. Simm and A. Aspuru Guzik, Mater. Horiz., 2016, 3, 226-233.

21 D. J. Scott, P. V. Coveney, J. A. Kilner, J. C. H. Rossiny and N. M. N. Alford, J. Eur. Ceram. Soc., 2007, 27, 4425-4435.

22 P. V. Balachandran, J. Theiler, J. M. Rondinelli and T. Lookman, Sci. Rep., 2016, 5, 13285.
23 S. Curtarolo, G. L. W. Hart, M. B. Nardelli, N. Mingo, S. Sanvito and O. Levy, Nat. Mater., 2013, 12, 191-201.

24 M. de Jong, W. Chen, R. Notestine, K. Persson, G. Ceder, A. Jain, M. Asta and A. Gamst, Sci. Rep., 2016, 6, 34256.

25 P. E. Dolgirev, I. A. Kruglov and A. R. Oganov, AIP Adv., 2016, 6, 085318.

26 V. C. Epa, A. L. Hook, C. Chang, J. Yang, R. Langer, D. G. Anderson, P. Williams, M. C. Davies, M. R. Alexander and D. A. Winkler, Adv. Funct. Mater., 2013, 24, 2085-2093.

27 R. Gomez-Bombarelli, J. Aguilera-Iparraguirre, T. D. Hirzel, D. Duvenaud, D. Maclaurin, M. A. Blood-Forsythe, H. S. Chae, M. Einzinger, D.-G. Ha, T. Wu, G. Markopoulos, S. Jeon, H. Kang, H. Miyazaki, M. Numata, S. Kim, W. Huang, S. I. Hong, M. Baldo, R. P. Adams and A. Aspuru-Guzik, Nat. Mater., 2016, 15, 1120-1127.

28 F. Hase, S. Valleau, E. Pyzer-Knapp and A. Aspuru-Guzik, Chem. Sci., 2016, 7, 5139-5147.

29 O. Isayev, D. Fourches, E. N. Muratov, C. Oses, K. Rasch, A. Tropsha and S. Curtarolo, Chem. Mater., 2015, 27, 735-743.

30 N. N. Kiselyova, A. V. Stolyarenko, V. V. Ryazanov, O. V. Senko and A. A. Dokukin, Russ. J. Inorg. Chem., 2016, 61, 604-609.

31 C. S. Kong, W. Luo, S. Arapan, P. Villars, S. Iwata, R. Ahuja and K. Rajan, J. Chem. Inf. Model., 2012, 52, 1812-1820.

32 T. C. Le, H. Yin, R. Chen, Y. Chen, L. Zhao, P. S. Casey, C. Chen and D. A. Winkler, Small, 2016, 12, 3568-3577.

33 Y. Liu, D. A. Winkler, V. C. Epa, B. Zhang and B. Yan, Nano Res., 2015, 8, 1293-1308.

34 A. O. Oliynyk, E. Antono, T. D. Sparks, L. Ghadbeigi, M. W. Gaultois, B. Meredig and A. Mar, Chem. Mater., 2016, 28, 7324-7331.

35 S. Srinivasan, S. R. Broderick, R. Zhang, A. Mishra, S. B. Sinnott, S. K. Saxena, J. M. LeBeau and K. Rajan, Sci. Rep., 2016, 5, 17960.

36 A. W. Thornton, D. A. Winkler, M. S. Liu, M. Haranczyk and D. F. Kennedy, RSC Adv., 2015, 5, 44361-44370.

37 D. A. Winkler, Toxicol. Appl. Pharmacol., 2016, 299, 96-100.

38 H. Xu, R. Liu, A. Choudhary and W. Chen, J. Mech. Design., 2015, 137, 051403.

39 U. Zavyalova, M. Holena, R. Schlögl and M. Baerns, ChemCatChem, 2011, 3, 1935-1947.

40 J. B. Goodenough and Y. Kim, Chem. Mater., 2010, 22, 587-603.

41 X. Han, Y. Gong, K. Fu, X. He, G. T. Hitz, J. Dai, A. Pearse, B. Liu, H. Wang, G. Rubloff, Y. Mo, V. Thangadurai, E. D. Wachsman and L. Hu, Nat. Mater., 2016, 16, 572-580.

42 J.-L. Reymond, Acc. Chem. Res., 2015, 48, 722-730.

43 N. Kireeva, I. Baskin, H. Gaspar, D. Horvath, G. Marcou and A. Varnek, Mol. Inf., 2012, 31, 301-312.

44 N. Kireeva, S. L. Kuznetsov and A. Y. Tsivadze, Ind. Eng. Chem. Res., 2012, 51, 14337-14343.

45 K. Klimenko, G. Marcou, D. Horvath and A. Varnek, J. Chem. Inf. Model., 2016, 56, 1438-1454.

46 M. Reutlinger and G. Schneider, J. Mol. Graphics Modell., 2012, 34, 108-117.

47 R. Wagner, G. J. Redhammer, D. Rettenwander, G. Tippelt, A. Welzl, S. Taibl, J. Fleig, A. Franz, W. Lottermoser and G. Amthauer, Chem. Mater., 2016, 28, 5943-5951. 
48 C. Bernuy-Lopez, W. Manalastas, J. M. Lopez del Amo, A. Aguadero, F. Aguesse and J. A. Kilner, Chem. Mater., 2014, 26, 3610-3617.

49 M. A. Howard, O. Clemens, E. Kendrick, K. S. Knight, D. C. Apperley, P. A. Anderson and P. R. Slater, Dalton Trans., 2012, 41, 12048-12053.

50 R. Jalem, M. J. D. Rushton, W. Manalastas, M. Nakayama, T. Kasuga, J. A. Kilner and R. W. Grimes, Chem. Mater., 2015, 27, 2821-2831.

51 D. Rettenwander, J. Langer, W. Schmidt, C. Arrer, K. J. Harris, V. Terskikh, G. R. Goward, M. Wilkening and G. Amthauer, Chem. Mater., 2015, 27, 3135-3142.

52 J. Wolfenstine, J. Ratchford, E. Rangasamy, J. Sakamoto and J. L. Allen, Mater. Chem. Phys., 2012, 134, 571-575.

53 D. Fourches, E. Muratov and A. Tropsha, J. Chem. Inf. Model., 2010, 50, 1189-1204.

54 D. Fourches, E. Muratov and A. Tropsha, Nat. Chem. Biol., $2015,11,535$.

55 D. Fourches, E. Muratov and A. Tropsha, J. Chem. Inf. Model., 2016, 56, 1243-1252.

56 R. D. Chirico, M. Frenkel, J. W. Magee, V. Diky, C. D. Muzny, A. F. Kazakov, K. Kroenlein, I. Abdulagatov, G. R. Hardin, W. E. Acree, J. F. Brenneke, P. L. Brown, P. T. Cummings, T. W. de Loos, D. G. Friend, A. R. H. Goodwin, L. D. Hansen, W. M. Haynes, N. Koga, A. Mandelis, K. N. Marsh, P. M. Mathias, C. McCabe, J. P. O'Connell, A. Pádua, V. Rives, C. Schick, J. P. M. Trusler, S. Vyazovkin, R. D. Weir and J. Wu, J. Chem. Eng. Data, 2013, 58, 2699-2716.

57 C. M. Powers, K. A. Mills, S. A. Morris, F. Klaessig, S. Gaheen, N. Lewinski and C. Ogilvie Hendren, Beilstein J. Nanotechnol., 2015, 6, 1860-1871.

58 C. O. Hendren, C. M. Powers, M. D. Hoover and S. L. Harper, Beilstein J. Nanotechnol., 2015, 6, 1752-1762.

59 I. Cortés-Ciriano and A. Bender, ChemMedChem, 2016, 11, 57-71.

60 C. Wang, Y. Gong, B. Liu, K. Fu, Y. Yao, E. Hitz, Y. Li, J. Dai, S. Xu, W. Luo, E. D. Wachsman and L. Hu, Nano Lett., 2017, 17, 565-571.

61 Z. Deng, Y. Mo and S. P. Ong, NPG Asia Mater., 2016, 8, e254.

62 Y. Wang, W. D. Richards, S. P. Ong, L. J. Miara, J. C. Kim, Y. Mo and G. Ceder, Nat. Mater., 2015, 14, 1026-1031.

63 Z. Lu, C. Chen, Z. M. Baiyee, X. Chen, C. Niu and F. Ciucci, Phys. Chem. Chem. Phys., 2015, 17, 32547-32555.

64 W. Li, E. Ionescu, R. Riedel and A. Gurlo, J. Mater. Chem. A, 2013, 1, 12239-12245.

65 K. M. Ok, P. S. Halasyamani, D. Casanova, M. Llunell, P. Alemany and S. Alvarez, Chem. Mater., 2006, 18, 3176-3183.

66 N. M. Halberstam, I. I. Baskin, V. A. Palyulin and N. S. Zefirov, Mendeleev Commun., 2002, 12, 185-186.

67 M. Nele, A. Vidal, D. L. Bhering, J. Carlos Pinto and V. M. M. Salim, Appl. Catal., A, 1999, 178, 177-189.

68 O. Wodo, S. Broderick and K. Rajan, MRS Bull., 2016, 41, 603-609.
69 Database on properties of chemical elements "Elements", http://phases.imet-db.ru/elements/main.aspx.

70 O. Ivanciuc, in Reviews in Computational Chemistry, ed. T. R. C. Kenny and B. Lipkowitz, 2007, pp. 291-400.

71 V. N. Vapnik, The Nature of Statistical Learning Theory, 2000.

72 C.-C. Chang and C.-J. Lin, LIBSVM: a library for support vector machines, 2001, software available at http://www. csie.ntu.edu.tw/ cjlin/libsvm.

73 L. Maaten, Proceedings of the IEEE International Workshop on Machine Learning for Signal Processing, 2012.

74 Principal Component Analysis, ed. I. T. Jolliffe, Springer, New York, 2002.

75 T. Thompson, A. Sharafi, M. D. Johannes, A. Huq, J. L. Allen, J. Wolfenstine and J. Sakamoto, Adv. Energy Mater., 2015, 5, 1500096.

76 N. Li, R. An, Y. Su, F. Wu, L. Bao, L. Chen, Y. Zheng, H. Shou and S. Chen, J. Mater. Chem. A, 2013, 1, 9760-9767.

77 C. Deviannapoorani, S. Ramakumar, M. M. Ud Din and R. Murugan, RSC Adv., 2016, 6, 94706-94716.

78 A. J. Martinolich and J. R. Neilson, Chem. Mater., 2017, 29, 479-489.

79 M. M. Ahmad and M. M. Al-Quaimi, Phys. Chem. Chem. Phys., 2015, 17, 16007-16014.

80 S. Narayanan and V. Thangadurai, J. Power Sources, 2011, 196, 8085-8090.

81 H. Peng, Q. Wu and L. Xiao, J. Sol-Gel Sci. Technol., 2013, 66, 175-179.

82 V. Thangadurai and W. Weppner, J. Am. Ceram. Soc., 2005, 88, 411-418.

83 V. Thangadurai, H. Kaack and W. J. F. Weppner, J. Am. Ceram. Soc., 2003, 86, 437-440.

84 V. Thangadurai and W. Weppner, J. Solid State Chem., 2006, 179, 974-984.

85 L. Truong and V. Thangadurai, Chem. Mater., 2011, 23, 3970-3977.

86 Y. X. Gao, X. P. Wang, W. G. Wang and Q. F. Fang, Solid State Ionics, 2010, 181, 33-36.

87 M. Kotobuki and K. Kanamura, Ceram. Int., 2013, 39, 6481-6487.

88 C. R. Mariappan, K. I. Gnanasekar, V. Jayaraman and T. Gnanasekaran, J. Electroceram., 2013, 30, 258-265.

89 Y. Wang and W. Lai, Electrochem. Solid-State Lett., 2012, 15, A68-A71.

90 W. G. Zeier, S. Zhou, B. Lopez-Bermudez, K. Page and B. C. Melot, ACS Appl. Mater. Interfaces, 2014, 6, 10900-10907.

91 J. Awaka, N. Kijima, Y. Takahashi, H. Hayakawa and J. Akimoto, Solid State Ionics, 2009, 180, 602-606.

92 I. Kokal, K. V. Ramanujachary, P. H. L. Notten and H. T. Hintzen, Mater. Res. Bull., 2012, 47, 1932-1935.

93 R. Murugan, V. Thangadurai and W. Weppner, J. Electrochem. Soc., 2008, 155, A90-A101.

94 R. Murugan, V. Thangadurai and W. Weppner, Appl. Phys. A: Mater. Sci. Process., 2008, 91, 615-620.

95 V. Thangadurai and W. Weppner, Adv. Funct. Mater., 2005, 15, 107-112. 
96 D. Rettenwander, G. Redhammer, F. Preishuber-Pflügl, L. Cheng, L. Miara, R. Wagner, A. Welzl, E. Suard, M. M. Doeff, M. Wilkening, J. Fleig and G. Amthauer, Chem. Mater., 2016, 28, 2384-2392.

97 W. H. Kan, L. Truong and V. Thangadurai, Ionics, 2014, 21, 373-379.

98 T. Zaiss, M. Ortner, R. Murugan and W. Weppner, Ionics, 2010, 16, 855-858.

99 A. Gupta, R. Murugan, M. P. Paranthaman, Z. Bi, C. A. Bridges, M. Nakanishi, A. P. Sokolov, K. S. Han, E. W. Hagaman, H. Xie, C. B. Mullins and J. B. Goodenough, J. Power Sources, 2012, 209, 184-188.

100 S. Ramakumar, L. Satyanarayana, S. V. Manorama and R. Murugan, Phys. Chem. Chem. Phys., 2013, 15, 11327-11338. 101 Y. X. Gao, X. P. Wang, W. G. Wang and Q. F. Fang, Solid State Ionics, 2010, 181, 33-36.

102 R. Murugan, V. Thangadurai and W. Weppner, Appl. Phys. A: Mater. Sci. Process., 2008, 91, 615-620.
103 C. Galven, G. Corbel, F. Le Berre and M.-P. Crosnier-Lopez, Inorg. Chem., 2016, 55, 12872-12880.

104 E. Rangasamy, J. Wolfenstine, J. Allen and J. Sakamoto, J. Power Sources, 2013, 230, 261-266.

105 L. Cheng, J. S. Park, H. Hou, V. Zorba, G. Chen, T. Richardson, J. Cabana, R. Russo and M. Doeff, J. Mater. Chem. A, 2014, 2, 172-181.

106 L. Buannic, B. Orayech, J.-M. López Del Amo, J. Carrasco, N. A. Katcho, F. Aguesse, W. Manalastas, W. Zhang, J. Kilner and A. Llordés, Chem. Mater., 2017, 29, 1769-1778.

107 Y. Matsuda, Y. Itami, K. Hayamizu, T. Ishigaki, M. Matsui, Y. Takeda, O. Yamamoto and N. Imanishi, RSC Adv., 2016, 6, 78210-78218.

108 H. Nemori, Y. Matsuda, M. Matsui, O. Yamamoto, Y. Takeda and N. Imanishi, Solid State Ionics, 2014, 266, 9-12.

109 X. Liu, Y. Li, T. Yang, Z. Cao, W. He, Y. Gao, J. Liu, G. Li and Z. Li, J. Am. Ceram. Soc., 2017, 100, 1527-1533. 